laid on quantitative inorganic analysis and on organic preparations involving modern methods of reduction, oxidation, condensation and so on. Short courses are also given on the application of semi-micro methods in both branches of chemistry. A reasonable variety of modern physico-chemical apparatus is available, the equipment including an absorptiometer (Spekker), a spectrophotometer (Coleman), microphotometer and spectroscope (Hilger), a chromatographic apparatus, an ultra-violet lamp and electrometric titration apparatus. A special feature is made of vacuum distillation; there are in the department molecular stills and various pumps, including a mercury pump combination (Towers) giving pressure of the order of 1 millibar. A laboratory fractionation column (Todd) has an efficiency of fifty theoretical plates. Each student gets an opportunity of making himself acquainted with the manipulation of the various pieces of apparatus.

The lecture courses and associated reading for the honours degree follow normal lines ; electronic theory may perhaps be regarded as a special feature. The students attend a series of lectures extending through. out the year in which the quantum mechanics of the hydrogen atom, bond formation, the periodic table and atomic structure, and applications of electron theory in organic chemistry are discussed in some detail. It has been found that the three-year general course, which includes physics and mathematics to a good pass-degree standard, is useful to the student in reading modern theoretical chemistry.

Students who obtain an honours degree may enter the research laboratories to work for the M.Sc. degre日; the work normally occupies one year. Various themes are studied; but at present the main work involves a study of the mechanism of base-catalysed reactions of the Claisen type with special reference to transformation reactions (see, for example, Proc. Roy. Dublin Soc., 24, 291 ; 1948).

The Nolan Laboratory (floor area 1,000 sq. ft.) is called after the late Prof. T. J. Nolan, who was professor of chemistry in the College during 1932-45. Prior to his comparatively early death, he had in conjunction with Prof. M. A. Hogan, professor of mechanical engineering, worked out the details of the course in chemical technology, but owing to the War was unable to make arrangements for the institution of the course. The laboratory contains apparatus to illustrate various unit chemical processes; this includes a centrifuge, a high-pressure (350 atmos. at $350^{\circ}$ ) autoclave of 5 litres capacity equipped with a stirring device and gas inlet (Cook), a 'Pyrex' glass fractionating column $3 \mathrm{ft}$. high, a steam-heated pan, a filter press, grinding equipment, high-temperature and vacuum ovens, and metering apparatus. Low.pressure steam and the other usual services are provided. The students receive lectures on the unit chemical operations which they study in the laboratory. At least half their time is spent in the Engineering Department of the College, where they have lecture courses on thermodynamics, materials of construction, workshop practice, fuel technology and electrotechnology. They also have practical instruction in the foundry, workshop, drawing office, and fuel and electrical laboratories.

In connexion with the planning of both the academic and industrial courses, it is desired to acknowledge valuable advice received from the heads of departments of a number of universities and colleges in Great Britain and from the Institution of Chemical Engineers.

\section{PREHISTORIC FLOODING IN THE SOMERSET LEVELS}

$T$ HE post-glacial history of the Somerset Levels has been the subject of considerable published work by Prof. H. Godwin and his collaborators in the pollen-analysis of peat; but a new series of "Studies of the Post-Glacial History of British Vegetation" reveals such a dramatic story as to appeal to more than specialists alone, although pollen-analysis and the study of macroscopical remains provide the scientific background of dating.

The unearthing and investigation of four distinct trackways through the raised bogs which lie between the Polden Hills and Wedmore Ridge are deseribed in the first paper by Prof. A. R. Clapham and Prof. Godwin (Phil. Trans. Roy. Soc. London, B, 233, $233-273$; 1948). Each is of particular interest, for, although appearing to be roughly contemporaneous, all represent different types of construction. The Meare Heath trackway is composed of transverse baulks of timber (mostly oak), many of which are perforated by mortise holes holding sharpened vertical piles. Long squared wooden stringers formed the margins of the track and indicate the use of wheeled traffic. The Shapwick Heath trackway, on the other hand, is of brushwood kept in place by stakes of various origins but including beech. Another trackway at Westhay is constructed from birch stems, the majority of which are laid longitudinally together with shaped, vertical stakes driven in to pin loose brushwood which prevented lateral displacement of the timbers. The shape of the axe-cuts on these timbers indicates a Late Bronze Age dating which is confirmed by other archæological remains. The Blakeway Farm trackway consists of overlapping faggots of very straight hazel poles which there is every reason to believe were derived from trees grown in a woodland system similar in its effects to present-day coppicing.

Each trackway was built upon the surface of a dry Sphagnum-Calluna bog; but in every case this appears to have been overwhelmed by flooding with the eventual formation of eutrophic Cladium fen. It is especially significant that they appear to have been submerged before suffering much hard wear, and a dramatic picture is drawn of the calamitous flooding of river-and lake-side colonies which caused a mass. evacuation over the improvised tracks.

The complementary paper bv Prof. Godwin (Phil. Trans. Roy. Soc. London, B, 233, 275-286; 1948) con. cerns the correlation between climate, forest. composition and prehistoric agriculture in the Somerset Levels. The most intense phases of agricultural activity appear to have occurred in the Middle and Late Bronze Ages and between Middle Iron Age and Middle Romano-British times, each being terminated by flooding of the raised bogs. Climatic change and not agricultural clearance is held to be the cause of changes in forest composition at the first flooding. The general nature of 'recurrence surfaces' is discussed, and it is pointed out that active bog-growth ceased in Romano-British times; but again this appears to have been the result of flooding by base-rich or brackish water and not an effect of Roman drainage schemes. The striking abundance of the remains of Scheuzeria palustris at the flooding surfaces contrasts strongly with its great scarcity at the present day (which is greater even than Prof. Godwin mentions, the species being extinct in 
England according to a forthcoming paper by Dr. W. A. Sledge in Watsonia).

Finally, a probable Early Iron Age dating for the monoxylous 'Shapwick Boat' is based upon the pollen-analysis of a sample of peat taken from the boat, and rounds off very neatly these outstanding contributions to the history of primitive man and his environment in Somerset.

H. G. BAKER

\section{PLASTICS INDUSTRY IN SCOTLAND*}

$\mathrm{T}$ HE reconstituted Committee on Plastics appointed by the Scottish Council (Development and Industry) was appointed to inquire further into the extent to which the industry is being developed in Scotland to meet requirements, to suggest what further action is required to meet the situation, and to consider in particular the possibilities of meeting the basic requirements of the industry from raw materials in Scotland. In its final report, the Committee states that while more firms are now manufacturing finished materials from moulding powders obtained from elsewhere, and the engineering industry is in a position to tackle the highly specialized side of mould fabrication without difficulty, no developments of any kind have occurred in the manufacture of the ingredients of the moulding powders. No plastics industry can be firmly established in Scotland while these raw materials have to be imported, and the supply of coal-tar phenol and cresols is quite inadequate to meet the needs of the plastics and other industries of the United Kingdom.

The Committee recommends, therefore, that the Ministry of Supply be reminded of the urgent need for synthetic phenol, and that ample benzene and sulphuric acid are available in Scotland for the purpose. The supply of toluene is also adequate, and the sulphonation process is regarded as more attrac. tive. Royal ordnance explosives factories in the west of Scotland appear to offer the most convenient sites for the manufacture of these phenols, and the Com. mittee also recommends that the Director of Ordnance Factories should be informed accordingly. The Tar Research Association should be invited to explore methods for efficient recovery of such products as $o$-xylene and naphthalene for phthalic anhydride manufacture, and the Ministry of Supply should also be asked to consider the possibility of manufacturing methyl alcohol in Scotland as soon as the fertilizer situation is relieved.

The increasing use of plastics of the polyvinyl chloride, methacrylate and other types focuses attention on the unsaturated gases, acetylene and ethylene. The oil-refining and shale-oil industries could produce large volumes of ethylene and propylene in plant now available in Scotland, and the Com. mitte accordingly recommends that the plastics and chemical industries should be advised that adequate amounts of unsaturated gases of the required purity for the manufacture of plastics and of antiseptics, insecticides, detergents and synthetic rubbers could be made available from the petroleum-refining and shale-oil industries and from coal carbonization in Scotland. Ethylene could also be recovered from cokeoven gas without seriously affecting the calorific

Final Report of the Committee on Plastics: Plastics in Scotland. Pp. 16. (Edinburgh: Scottish Council (Development and Industry), 20 George Street, 1948.) 28. value of the gas for most industrial purposes, and the Committee recommends that the coke manufacturers be encouraged to investigate this possibility.

Since five per cent of the estimated power of the hydro-electric schemes set apart for calcium carbide manufacture would make a substantial contribution to the needs of the plasties industry in Scotland for acetylene, it is recommended finally that the Secretary of State be informed of the urgent need of an established carbide industry in Scotland for chemical as well as engineering purposes. The Committee concludes by pointing out that the rapidly increasing developments in the manufacture of flexible plastic materials emphasizes the need for a wide range of suitable plasticizers, none of which is at present made in Scotland.

The economic aspects of the whole situation are not discussed in this report; this may well draw serious criticism from the economists for neglect of an essential factor.

\section{THE NATIONAL FOUNDATION FOR ADULT EDUCATION}

$T$ HE National Foundation for Adult Education has now been constituted since January 1947 and, besides its quarterly bulletin, Foundation Papers, has published various supplements dealing with subjects of immediate importance to its corporate members.

One supplement, "Voluntary Agencies in Adult Education", contains a summary of the aims and activities of voluntary bodies working in the field of adult education. Since there is no up-to-date and comprehensive directory of adult education, the information contained in this supplement should be of particular use to local education authorities in coming to grips with the development plans for further education which they bave been asked to prepare. "Voluntary Agencies in Adult Education" will also be useful as a reference for individuals who are interested in various aspects of adult education. The supplement contains no reference to the work of university extra-mural departments and tutorial class committees, and it is intended that these should be considered in a later supplement.

The second supplement, called "Sources of Visual Aid Material : For use in the Adult Teaching of History and Contemporary Affairs", has been compiled by the deputy director, Extra-Mural Depart. ment, University of Manchester. The information has been collected partly at the request of the Associa. tion of Tutors in Adult Education and partly to meet the needs of tutors of the Manchester University Extra-Mural Department. It should also be useful to leaders of discussion groups and others concerned with adult education classes. The booklet contains a list of maps and charts, films, filmstrips, lantern slides and other pictorial material which would be suitable for adult classes of a general historical and geographical nature, and also a list of material suitable for teachers dealing with particular periods and countries.

Another supplement, "Accommodation for Adult Education : Some Examples and Suggestions", discusses an issue which presents difficulties to all the co-operating parties in adult education. A recent pamphlet of the Ministry of Education stated that : "Up and down the country there are a few colleges 